\title{
Unintended consequences: cathedral arch distress due to roof integration
}

\author{
M. Farmer \& F. Peters \\ Wiss, Janney, Elstner Associates, Inc., Virginia, USA
}

\begin{abstract}
This project involves one of the largest cathedrals in the United States. Built in the 1950s, the exterior walls are limestone-faced brick masonry bearing walls. The roof structure is composed of reinforced, cast-in-place concrete slabs, joists, and beams, decoratively painted and exposed to the interior. The roof structure is supported by 14 limestone-faced masonry arches - the arches are approximately 30 inches thick. In 1972 a limestone fragment fell from a 90 foot high limestone masonry arch to the Sanctuary floor. Our investigation revealed that concerns regarding limestone failure were initially raised 10 years after the original construction. It was determined that control joints in the concrete roof structure were located directly over the arches, and the concrete members were placed directly in contact with the limestone arches without any ability for the arch masonry to accommodate the inevitable volume changes and movements of the roof structure. These differential movements between the concrete structure and the limestone arches have caused substantial damage to the limestone masonry and the concrete roof structural members, threatening the overall stability of both. The objective of this project was to stabilize the limestone arch masonry and reduce the potential for future distress by disengaging the roof structure from the arches to the greatest extent possible without critically compromising bearing of the roof structure on the arches. This challenge led to a series of targeted modifications to the concrete roof structure to overcome the damage it has sustained, and stone masonry repairs to isolate the roof structure's influence on the arches.
\end{abstract}

Keywords: cathedral, arch, roof, stone, concrete, joints, movement, structure, distress, repairs. 


\section{Background}

The Cathedral of Mary Our Queen is located in Baltimore, Maryland. The Cathedral was dedicated in 1959 (fig. 1) and was constructed over a period of five years. The structure is generally a cruciform in plan with the Nave and Sanctuary comprising the main body of the plan (the length oriented along an east/west axis) and smaller chapels to the north, south and west, the Baptistery to the south, and Sacristy to the north. The Cathedral is 373 feet long, and 132 feet wide; the height to the spires above the bell towers is 163 feet.

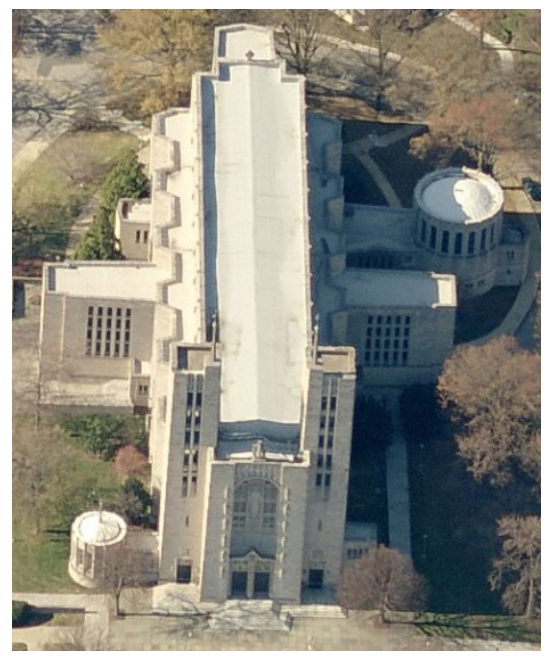

Figure 1: Aerial view of the Cathedral, highlighting the main roof, bell towers, and main entrance.

In 2008, a 10 pound limestone fragment fell from an arch over the sanctuary and landed on a pew below. The event occurred during the night when the Cathedral was not in use. Our firm was engaged to investigate the cause of the distress observed in the limestone masonry arches above the Nave and Sanctuary.

\section{Limestone arch and roof construction}

The main (uppermost) roof covers the Nave and Sanctuary. It is composed of reinforced concrete purlins, rafters, and one-way slabs (fig. 2). The roof structure is supported on the limestone masonry arches that span from north to south over the Sanctuary and Nave. The arches are approximately 90 feet tall and span approximately 46 feet (fig. 3). The roof structure consists of a sloped center section with a ridge that runs east/west; purlins span from arch to arch at the center (ridge purlins) and at the base of the slope to the north and south (intermediate purlins). Concrete rafters span between the purlins, and 4 inch thick one-way concrete slabs that span between rafters. Purlins are also present 


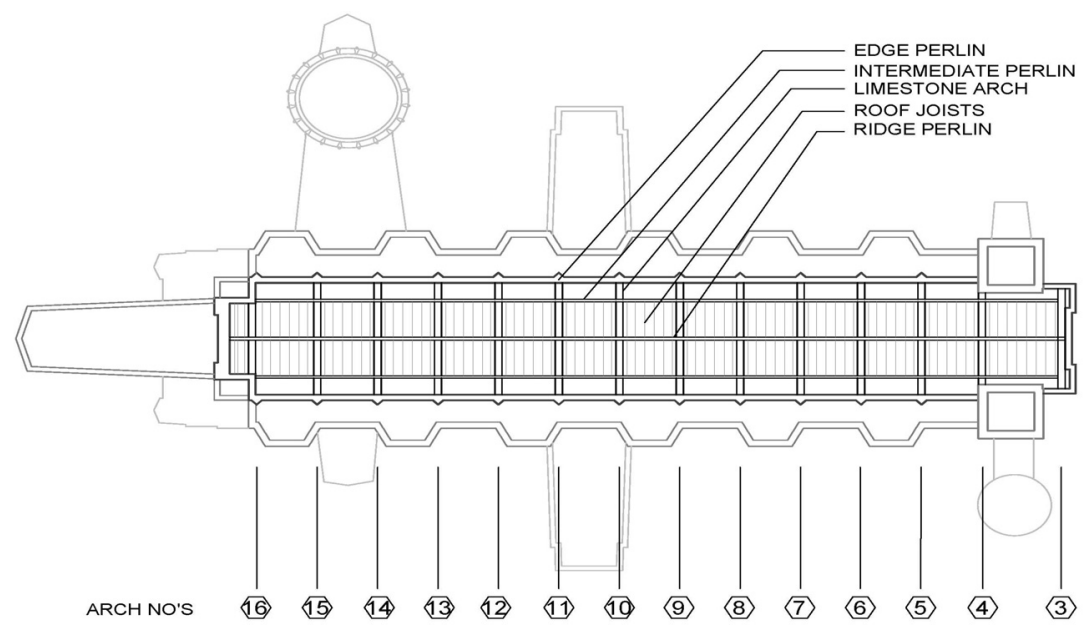

Figure 2: Plan view of the Cathedral and roof layout, highlighting the various main roof structural elements.

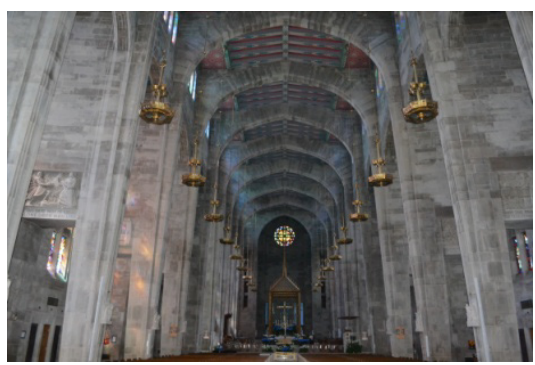

Figure 3: View of the main roof structure and supporting arches from the Sanctuary.

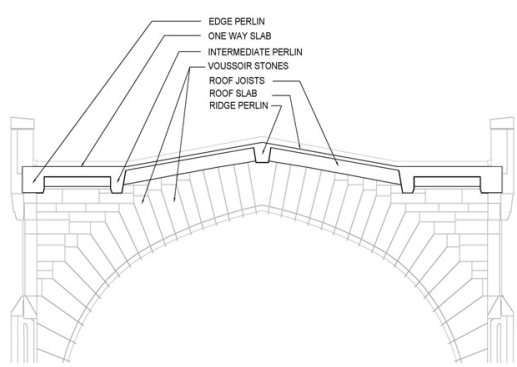

Figure 4: Diagram of a typical masonry arch and the roof structural components.

at the north and south edge of the main roof; an 11 inch thick one-way concrete slab spans between the edge purlins and the intermediate purlins (fig. 4).

The support points for the roof structure, or arch centerlines, are defined as part of the structural grid in the original construction documents, so each arch has a corresponding number. The first arch at the east end of the Sanctuary (adjacent to the choir loft) is identified at gridline 3; the numbers increase east to west. The concrete roof structure is divided into sections at control joints that are centered over arches at gridlines $4,7,10$, and 13. The original construction detail of the typical control joint at the slope roof structure illustrates the 4 inch thick sloped concrete slab interrupted by a 1 inch gap at the centerline of the masonry arch below. The joint is shown carrying through the concrete support purlins, but not through the arch (fig. 5). 
The arches are constructed of solid masonry. The arch pier and voussoir stones are solid limestone; the buttress portion of the arch is typically limestone veneer in an ashlar pattern over clay brick masonry. Solid limestone is indicated in the original drawings below all roof purlin bearing points. Structural clay tile is shown on the construction documents above the arch as infill between the solid voussoir stones and the concrete roof structure above. The structural clay tile is flanked on each side by limestone veneer.

\section{Condition assessment}

\subsection{Limestone arches}

After the limestone fragment was discovered, a visual inspection of all the arches was performed using high power optics and high intensity lighting. Additional locations of potentially unstable limestone were identified, and the pews below them cordoned off to limit seating below these areas. The original drawings, construction-related correspondence, and numerous construction photographs were also reviewed to understand the as-designed construction of the arches, and any prior history of concerns with respect to their stability.
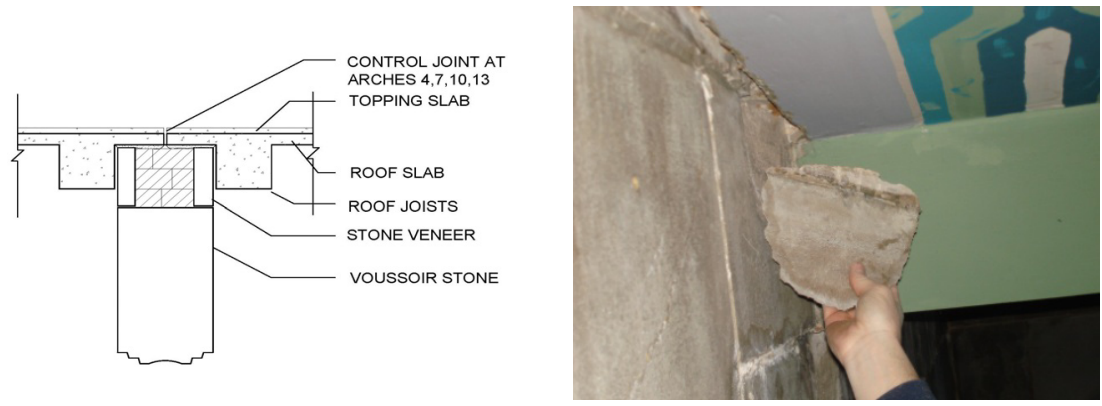

Figure 5: Typical masonry arch Figure 6: Typical spall and construction. The control limestone damage joint is present in the roof structure but not the arch. observed and removed from the arches.

Scaffolding was then erected to visually examine at close range the arch from which the limestone fragment fell (Arch No. 10). Manual sounding of all arch units and Ultra-sonic Pulse Velocity (UPV) testing of several selected representative arch stones was also performed to assess their integrity. All existing distress, previous repairs, and details of the arch interface with the concrete roof structure were documented. Damage in the form of chips, spalls, and insipient spalls, as well as previous repairs were found. Several loose and unstable fragments were removed from Arch No. 10 to better assess its as-built condition and limit future risk of stone instability (fig. 6).

A custom-built mobile personnel lift with sufficient reach to access the apex of the arches was used to inspect all of the arches for evidence of instability; 
damage similar to that observed at Arch No. 10 was also found at Arch Nos 4, 7, and 13. The other arches appeared to be in good condition with little or no stone damage. Much of the damage and repairs were located at or adjacent to the purlins where they were bearing on the arches (fig. 7). Repairs included fragments re-attached with metal pins and structural adhesive (fig. 8). Dutchman repairs (replacement of the outer face of the stone cut to fit the dimensions of the deteriorated stone) were also evident, primarily at the ridge and intermediate purlin bearing areas. Of great concern was the depth of stone damage at these bearing points; if the bearing stones were damaged to a depth that reduced the bearing area for the purlins to unsafe limits, then structural modifications to the arches or the roof structure would be required.

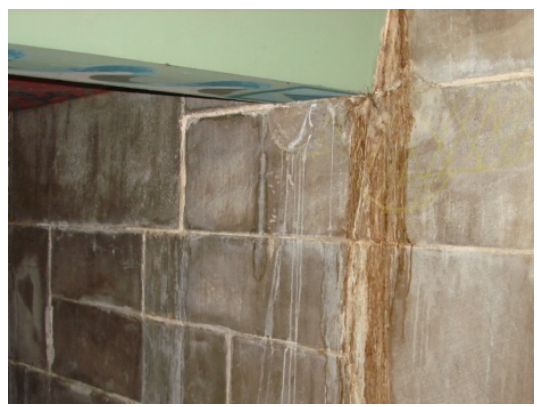

Figure 7: Typical damage associated with the purlin bearing on the arches.

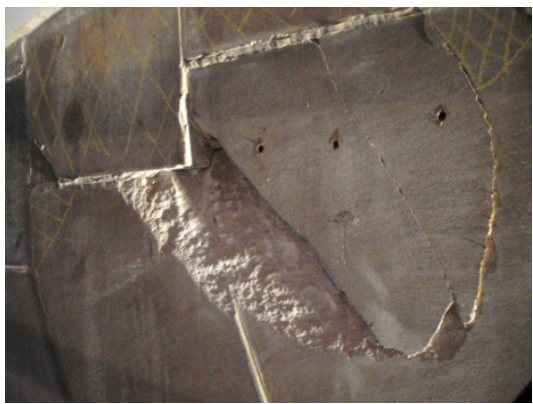

Figure 8: Several stone fragments were reattached using resin adhesive and brass pins.

UPV testing and manual sounding determined that there are several stones that were depicted as solid on the original architectural drawings were actually only a 6 inch thick veneer placed over the structural clay tile infill. It also confirmed that numerous arch stones were cracked behind the surface of the veneer, though there was no visual evidence of cracking. There was also evidence of substantial water infiltration including efflorescence at joints and staining. Water staining was predominantly located at Arch Nos 4, 7, 10, and 13, below the flat section of roofing between the edge and intermediate purlins (fig. 9).

\subsection{Concrete roof structure}

To better understand the relationship between the roof structure and the arches, a roofing contractor was engaged to make inspection openings above three of the arches (Arch Nos 4, 10, and 13) where substantial limestone distress was observed. These openings revealed a clear joint at some locations through both the lightweight concrete topping slab and the structural slab; at other locations the lightweight topping was cracked, but lacked a formed joint. Felt paper was observed over the joint between the topping and the structural slab. The "joint" at each of Arch Nos 4, 10, and 13 varied in width from 1 to 2 inches. As part of 


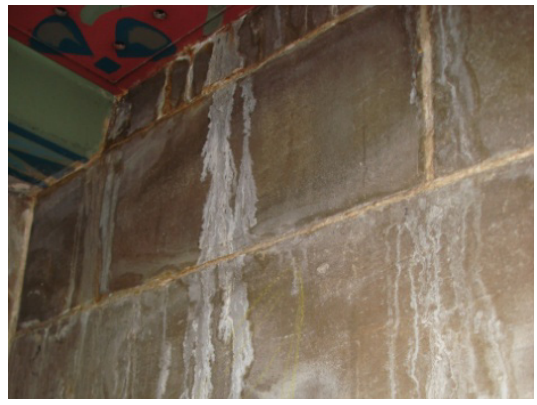

Figure 9: Staining and efflorescence visible on Arches 4, 7, 10, and 13 indicative of water infiltration from above.

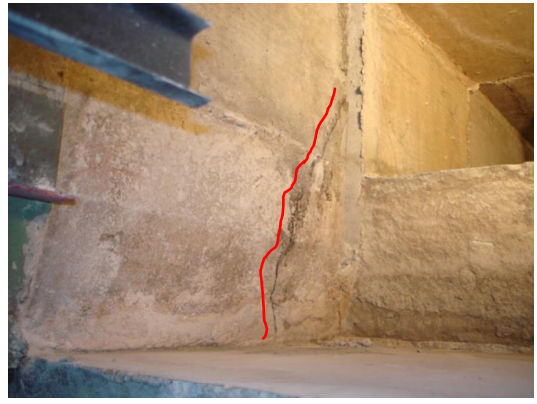

Figure 10: Cracking in the purlin ends at the bearing, compromising their shear load capacity.

this effort, numerous roof membrane blisters were observed, as well as areas of wet roof insulation.

When the stone masonry adjacent to the purlins was removed, it was discovered that the ends of several were cracked due to restraint and a lack of reinforcement continuity (fig. 10). The cracking reduced the purlin's effective bearing area. The end damage was most severe at the ridge purlins where, combined with the reduced bearing surface resulting from previous bearing stone damage, the remaining effective bearing area was deemed insufficient to safely support the ridge purlins. This necessitated major modifications of the concrete roof structure to increase the ridge purlin bearing area.

\section{Findings}

Our investigation revealed that the limestone fragment that fell from the arch was part of a limestone veneer stone installed over structural clay tile masonry at the top portion of the arch above the solid voussoir stones. It was confirmed that additional fragments were present and that prior repairs were performed in an effort to retain other limestone fragments. Based on a review of available documents, we determined that a structural engineer was previously engaged by the Cathedral to investigate a similar occurrence of limestone failure in 1972. 
The repairs conducted at that time included removal of some unstable fragments, as well as application of structural adhesive and metal dowels to re-attach other stone fragments.

Our investigation found that similar damage and previous repairs were performed at Arch No.'s 4, 7, 10, and 13. It also revealed that a number of the stones within the arches that were to be solid were actually veneer stones over brick or clay tile masonry back-up.

Arch No.'s 4, 7, 10 and 13 coincide with the locations of control joints within the concrete roof structure identified on the original construction drawings. There are no provisions within the stone masonry of the arch to accommodate the control joints. The control joints were presumably incorporated in the concrete roof structure to accommodate movement due to plastic drying shrinkage and volume changes resulting from thermal cycles, as well as to separate the concrete placements. Plastic drying shrinkage occurs early in the life of a concrete structure, as the concrete cures and changes from its plastic, flowable state to its eventual rigid state. The material volume decreases proportionally to its dimensions as water within the concrete is used for hydration of the cement and the remainder evaporates from the material. The exact amount of shrinkage undergone by a concrete structure is a function of several factors, including the cement content, the water/cement ratio, method of curing, and its normalized moisture content. Dimension change due to shrinkage can be as much as 1/8 inch in 20 feet [1]; the distance between expansion joints in the roof structure is approximately 63 feet. If the concrete is unable to slide across the supporting arch, then this displacement is imparted to the arch masonry.

Over time a concrete structure also undergoes volume changes as a result of temperature fluctuations. As the roof structure at the Cathedral gets warmer, such as during the summer, the concrete increases in volume resulting in a length increase between joints. In the winter months, the concrete is cooler and reduces in volume, causing the concrete sections to shorten. To accommodate these seasonal changes in dimension, the concrete moves across the arch masonry at the expansion joint, making the joint width wider or narrower. If the concrete is unable to move smoothly across the rigid arch masonry, then the masonry itself can be dragged along or otherwise damaged as the concrete structure contracts. When the cycle is reversed, the arch masonry can become bound up by debris and be unable to move back to its original position, so the concrete slips back over. During the next contraction cycle, the masonry can move again, causing irreversible, net movements that result in cracks or spalls once the limit of tensile strength within the stone is reached.

Movement associated with thermal expansion and contraction is dependent on the actual temperature range experienced and the length of concrete structure between joints; we estimated a range of approximately 30 deg. F for the assembly given local environmental conditions, the internal heating and air conditioning capacities, and the thermal efficiency of the roof assembly. This range would produce an approximate change in length of $1 / 8$ inch in the roof structure between control joints [2]. Even roof structure movements of this 
magnitude could have a significant effect on the stability of the stone masonry in contact with the concrete.

Given the age of the Cathedral, the shrinkage effects on the concrete roof structure have likely reached a negligible level; however, continued future damage is likely due to ongoing thermal effects and the potential for disruption of previously damaged stone masonry despite prior repair attempts in 1974 . The stone masonry damage that has occurred since 1974 indicated that the conditions that led to the current occurrences of stone instability will likely continue to occur.

The concrete roof purlins and roof slab were installed directly over the arches, using the limestone masonry units as forms; there were no provisions to isolate the concrete structure from the adjacent stone masonry units. The bond between the concrete and the masonry forces the limestone and clay masonry infill to move with the concrete where it is free along the control joints in the roof structure.

The roof structural system is designed such that the loads at the flat roof areas are transferred from the flat edge slabs directly to the purlins; at the sloped portions of the roof, the load is transferred from the sloped slabs to the rafters, which in turn shed load to the purlins. The purlins "sit" on the arches, and transfer their load into the arches through bearing. As with any reinforced concrete structural member, the purlins will deflect under load, and the ends of the purlin will rotate slightly. This deflection increases the bearing stress at the surface of the arch masonry supporting the purlins causing the observed distress.

Our investigation confirmed the damage of the limestone at the arches (of both solid stones and veneer stones) is caused by movements of the concrete roof structure at the expansion joints pulling or dragging the limestone veneer (and clay tile behind the veneer) of the arch masonry that is in contact with the concrete roof structure as it contracts between the joints. The damage of the limestone masonry below and adjacent to the purlin bearing points on the arch is the result of shear friction induced tensile stresses in the stone caused by movement of the purlins across the arch masonry and the higher bearing stresses at the face of the arches due to deflection of the purlins under load.

\section{Solutions}

To eliminate any potential for future masonry damage resulting from movement of the concrete roof structure, it would be necessary to completely isolate the concrete from the arch masonry. This would require modifications to all roof-toarch bearing points, to the concrete slab where it overlaps the arch masonry, and to the limestone directly below the roof edge slabs. While these efforts are theoretically feasible, they would be both costly and highly disruptive to the Cathedral, primarily due to the difficulties associated with temporarily redirecting the existing structural loads at the purlin bearing points.

In the absence of completely isolating the roof structure from the arches, our approach to substantially reducing the risk associated with future movements of the concrete structure relative to the stone arches involved stabilizing immediate 
structural and safety concerns, isolating the roof structure from the arches to the greatest extent possible, anticipating additional damage to the limestone and controlling any future failures, and enabling aggressive monitoring of the arch masonry over time in an attempt to identify potentially unstable material prior to its complete disengagement.

\subsection{Immediate stabilization/repair}

All limestone that was found to be unstable was repaired using traditional techniques of replacement, dutchman installation, epoxy injection, and supplemental anchoring. Every effort was made to repair the stone in place, provided the appearance of the repairs would be acceptable.

Due to the damage observed at the concrete ridge purlins and the limestone bearing below, major structural repairs were required to assure adequate load transfer from the ridge purlin to the arch. Supplemental haunches were designed and installed that expanded the bearing area to engage more of the stone below. The haunches were constructed to engage the concrete joist adjacent to the arches through tensioned rods (grouted after tensioning). A steel plate on the interior of the joints was required to fully develop the tensile loads required. The haunch bearing surface includes Teflon coated bearing plates mounted in the haunch and on the stone below to provide a virtually frictionless bearing condition (fig. 11). It was determined that installation of the haunches would be most efficiently accomplished by removing the section of the concrete roof slab over the arches and the infill material above the keystone. This material was removed above the arch on both sides of the ridge purlin ends down to the keystone itself (fig. 12). Since the keystone was originally notched to serve as a form for the concrete ridge purlin, the surface of the keystone adjacent to the purlins was lowered to the purlin bearing plane. This provided for greater haunch depth. If the original bearing area or the ridge purlin became further

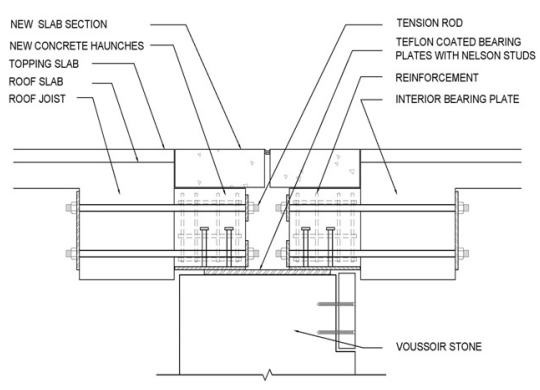

Figure 11: Supplemental haunch design. Note the bearing plates for tension rods and slide bearing plates at the arch surface.

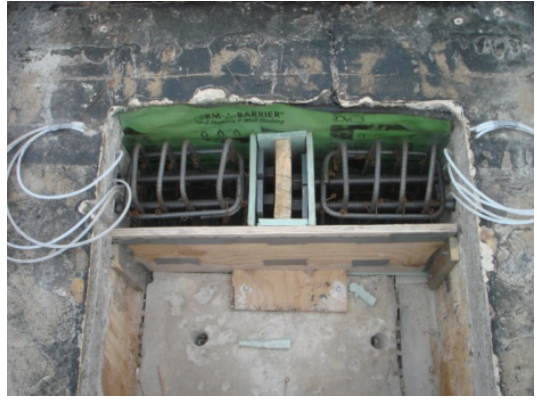

Figure 12: New haunch installation, including reinforcement and grouted tension rods. Haunches were cast on both sides of purlins. 
compromised due to future differential movements between the arch and the purlin, the new haunches will be engaged to provide additional bearing support for the roof load and continue to perform as the primary bearing element without damaging the arch stone masonry below. This method was deemed less visible and invasive than modifications to the arch to increase the bearing area.

\subsection{Roof structure/arch isolation}

Isolation of the concrete roof structure from the arch masonry was improved in several ways. First, the section of concrete roof slab that extended over the arches and between the ridge and intermediate purlins was isolated so it could no longer drag the arch masonry below during movement cycles (fig. 13). While cutting this slab section free diminished the capacity of the roof joists adjacent to the arch somewhat, the remaining joist capacity was more than adequate to carry the anticipated design loads. This repair was accomplished using a concrete chain saw and walk behind concrete saw. The challenge was providing complete isolation while not over-cutting and damaging the adjacent purlins or joists (fig. 14).

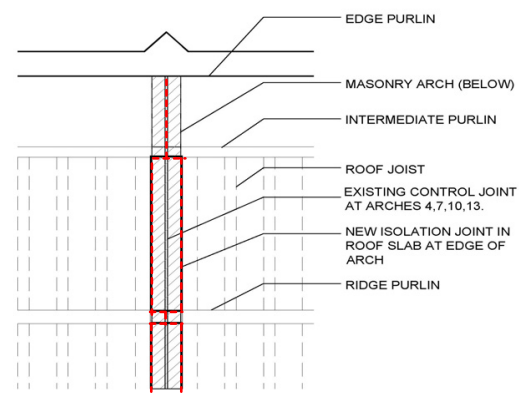

Figure 13: Layout of original and new control joints above arches $4,7,10$, and 13 .

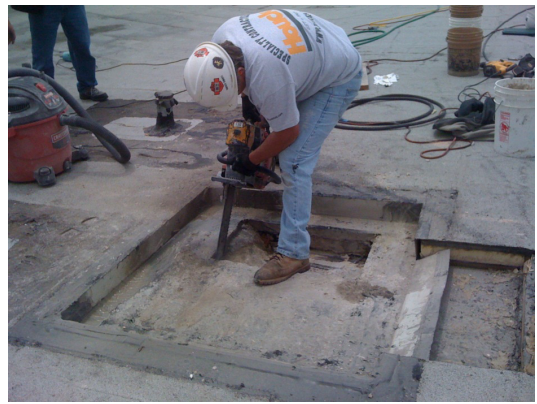
Figure 14: Cutting new control joints with concrete chainsaw to avoid purlins.

To address the potential for damage of the stone directly below the bearing points of the purlins, all loose, unstable material and prior dutchman repairs were removed. The bearing stone was then excavated to a depth of approximately 3 inches, recessing the outermost edge of the purlin bearing. A 2 inch thick limestone facing was then installed with a cavity behind it using dowels set in structural adhesive and extending past the theoretical failure plane that would result from a bearing failure (fig. 15). The facing was completely isolated at its perimeter with sealant and able to accommodate slight rotations of the concrete structure without damage. By installing this repair, the critical bearing zone was confined behind the stone facing; therefore, any future spalling resulting from bearing stresses or structural movements would be contained behind the stone facing and not pose a risk to the parishioners below (fig. 16). 


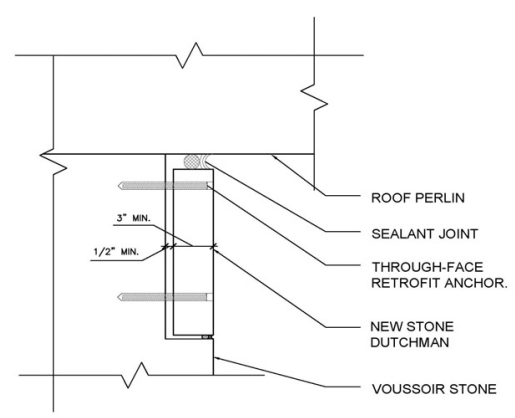

Figure 15: Typical dutchman repair isolated from purlins at bearing points.

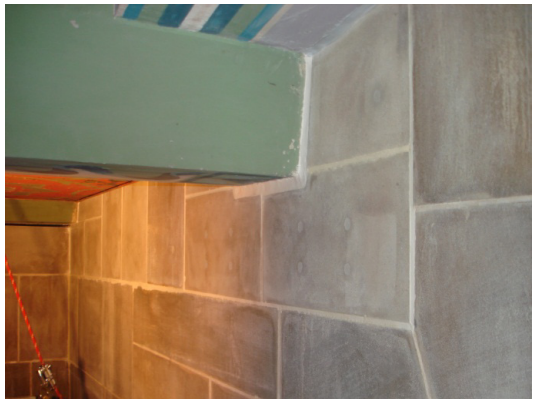

Figure 16: Finished dutchman repairs isolated from purlins at the bottom and sides.

Because we found that the concrete was placed directly against the surrounding stone masonry units, it was also critical to isolate the sides of the purlin from the stone. At the end purlins and one side of the intermediate purlins, the stone adjacent to the purlins could be removed and reinstalled with a clear space to allow for future movement of the purlin. Where this was not possible at the sloped side of the intermediate purlin, the joint between the purlin and the stone was line drilled to reduce the contact surfaces and disrupt the stone/concrete bond.

\subsection{Interior access system}

Based on our experience using fixed scaffolding during our investigation of the arch distress, it was clear that access for the immediate and future repairs would be a significant factor. As part of the work, we devised and engineered a through-roof scaffold suspension system to provide access to the arches, the side walls, and the underside of the roof. The system utilizes rigging sleeves that are installed through the roof slab. The rigging sleeves allow cables to be passed through them to support suspended scaffolding. The sleeves are also designed to be used as tiebacks when not in use for primary suspension. We also designed a supplemental frame or "sled" to be used as a tieback or primary suspension point directly over a rigging sleeve (fig. 17). The rigging sleeves are enclosed above the roof in an insulated box to limit condensation. At the interior, the sleeves are trimmed with a cap and lanyard that can be lowered from the roof to allow for suspension cable installation (fig. 18).

\subsection{Roof system}

To address the ongoing water leakage issues and accommodate the structural modifications to reduce the potential for future limestone arch distress, as well as implement a through-roof interior rigging system to enable inspection and repair 


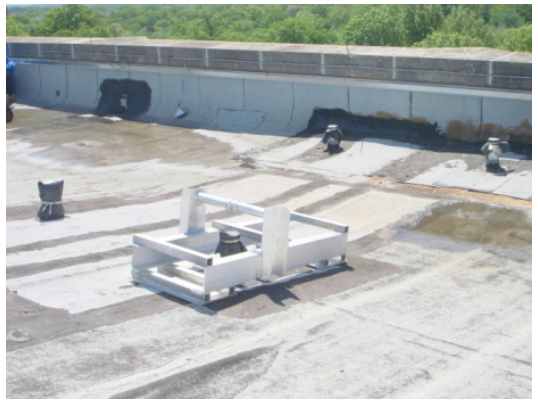

Figure 17: Rigging sleeves on either side of the arches prior to the new roof installation, and the support "sled."

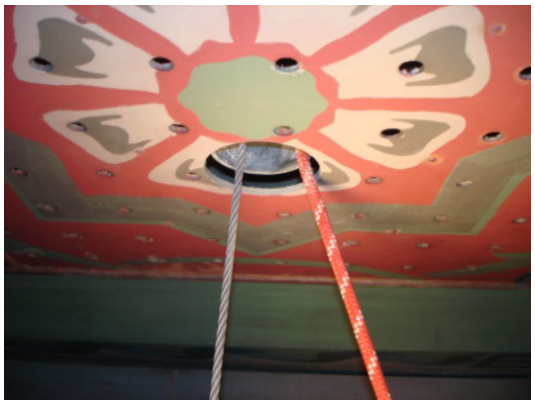

Figure 18: Rigging sleeve at interior. Trim caps (not shown) are finished to match ceiling.

of the arches, the roof assembly would have required substantial modifications and repair. Given the level of roof assembly disruption that is required to implement this work and the reportedly poor roof performance to date, it was determined that complete replacement of the main roof assembly was prudent.

We also noted that the insulation of the roof system serves to moderate the range of temperatures the roof undergoes and thereby the associated volume changes and the range of temperature fluctuations experienced by the roof structure may be reduced by incorporating more effective insulation in the roof system. Volume change will continue to occur as long as the roof slab experiences temperature variation; however, the magnitude of the volume changes would be proportionally reduced as the insulating value of the roof increases. This in turn should reduce the frequency and magnitude of additional limestone fragmentation or instability as the roof structure moves across the arch elements.

\section{Summary}

This Cathedral is a monumental structure. While well intentioned, the incorporation of control joints into the roof structure without adequate provisions for differential movement precipitated a near catastrophic and costly repair program. The recent repairs were designed to minimize their impact on the Cathedral and its parishioners (religious services continued uninterrupted during the work), mitigate as much risk of future distress as technically feasible and financially feasible, and facilitate future repair work that will be necessary to maintain this majestic structure. We are hopeful that these repairs will restore stability to the structure and become favorably integrated into the building's history and physical fabric. 


\section{References}

[1] ACI 224.1R-07, Causes, Evaluation, and Repair of Cracks in Concrete Structures, ACI International, Farmington Hills, MI, p. 3.

[2] ACI 224.1R-07, Causes, Evaluation, and Repair of Cracks in Concrete Structures, ACI International, Farmington Hills, MI, p.4. 